\title{
Isolation and characterization of antimicrobial compounds from Cotinus coggygria Scop. ethyl acetate extract
}

\author{
Ali Șen ${ }^{1}$ (D) Ayșe Seher Birteksöz Tan² (D), Șükran Kültür ${ }^{3}$ (D), Leyla Bitiș (i) \\ 'Marmara University, Faculty of Pharmacy, Department of Pharmacognosy, İstanbul, Turkey \\ ${ }^{2}$ Istanbul Univesity, Faculty of Pharmacy, Department of Pharmaceutical Microbiology, İstanbul, Turkey \\ ${ }^{3}$ Istanbul Univesity, Faculty of Pharmacy, Department of Pharmaceutical Botany, İstanbul, Turkey
}

ORCID IDs of the authors: A.Ș. 0000-0002-2144-5741; A.S.B.T. 0000-0003-2123-1468; Ș.K. 0000-0001-9413-5210;

L.B. 0000-0003-1167-6666

Cite this article as: Sen, A., Birteksoz Tan, A.S., Kultur, S., \& Bitis, L. (2020). Isolation and characterization of antimicrobial compounds from Cotinus coggygria Scop. ethyl acetate extract. Istanbul Journal of Pharmacy, 50 (3), 272-276.

\begin{abstract}
Background and Aims: Cotinus coggygria leaves are traditionally used in the treatment of various diseases, including their use for antifungal purposes. The aim of this study was to evaluate the antimicrobial activity of the extracts of $C$. coggygria and to discover compounds that may be responsible for the activity of the most active extract.

Methods: The antimicrobial activities of extracts and compounds were assessed by the microbroth dilution technique. Major compounds of active extract were isolated using chromatographic methods and identified by spectroscopic methods.

Results: Diethylether (CCD), ethyl acetate (CCEA), methanol (CCM), ethanol (CCE) and water (CCW) extracts of $C$. coggygria exhibited noticeable antifungal activities against Candida albicans with MIC values of $39,4.9,4.9,4.9$ and $9.8 \mu \mathrm{g} / \mathrm{mL}$, respectively. Also, CCEA extract showed good antibacterial activity against Proteus mirabilis with an MIC value of $156 \mu \mathrm{g} / \mathrm{mL}$. Two major compounds, gallic acid and methyl gallate, were isolated from CCEA, the most active extract. Gallic acid was found to be highly active against $C$. albicans and $C$. tropicalis with an MIC value of $9.8 \mu \mathrm{g} / \mathrm{mL}$ (for both fungi). In addition, gallic acid showed moderate antimicrobial activity against Staphylococcus aureus, S. epidermidis and C. parapsilosis with MIC values of 78,156 and $156 \mu \mathrm{g} / \mathrm{mL}$, respectively.

Conclusion: This study is the first study to reveal the compounds responsible for the activity of CCEA extract with antifungal activity. These results suggest that gallic acid, along with other phenolic compounds, is responsible for the antifungal activity of CCEA. Also, it confirms the ethnobotanical use of $C$. coggygria for antifungal purposes.

Keywords: Antimicrobial activity, Candida species, Cotinus coggygria, ethyl acetate extract, gallic acid, methyl gallate
\end{abstract}

\section{INTRODUCTION}

Infectious diseases, especially in tropical and developing countries, are responsible for more than $50 \%$ of deaths worldwide, according to World Health Organization (WHO) reports (Zhang et al., 2013). At the same time, microbial contamination is one of the major concerns of the food and pharmaceutical industries, and the increasing tendency of microorganisms to develop resistance to existing antibiotics has led researchers to find new antimicrobial agents (Singh, Pandey, Agnihotri, Singh, \& Pandey, 2017). Recent scientific studies have shown that there is a significant agreement between the traditional use of plants by the people in the treatment of specific symptoms and the experimental studies carried out in the laboratory such as anti-bacterial, anti-fungal, anticancer, and antiviral activities (Zhang et al., 2013). At the same time, the fact that Cotinus coggygria, which is used for wound-he-

Address for Correspondence:

Ali ȘEN, e-mail: ali.sen@marmara.edu.tr; alisenbjk@gmail.com 
aling purposes, has shown an important wound-healing effect on normal and diabetic wounds in the previous pharmacological studies conducted by our team supports this idea (Aksoy et al., 2016a; Aksoy et al., 2016b). Various compounds with antimicrobial activity have been isolated from higher plants, and many of these compounds have shown promising potential to treat infectious diseases (Madikizela, Aderogba, Finnie, \& Van Staden, 2014). Therefore, it is important to conduct research on plants to discover promising new and natural antimicrobial compounds or products.

The genus Cotinus, a member of the Anacardiaceae family, is represented by a single species in Turkey (Davis, 1967). This species is C. coggygria and the leaves of this species are used directly fresh, or in the form of an infusion or decoction. Leaves of $C$. coggygria have been used in the treatment of stomach pain, gastritis, ulcer, cuts, burns, wounds, eczema, fractures, diabetes, urinary diseases, cardiac diseases, kidney stones, nephritis, cancer, cough, abdominal pain, arm numbness, asthma, hemorrhoids, enteritis and anthrax in Turkey. It is also used as an antifungal, antihypertensive and a vasodilator (Kültür, 2007). Previous studies on phytochemical analysis of C.coggygria indicated the presence flavonoids (fisetin, fustin, sulfuretin, myricetin, quercetin, myricetin-3-O- $\alpha$-rhamnoside, myricetin3-O- $\beta$-galactoside, 2,10-oxy-10-methoxysulfuretin, cotinignan A, sulfuretin, 2,3-trans-fustin, fisetin, butin, butein, taxifolin, eriodictyol, 3',5,5',7-tetrahydroxyflavanone, 3,4',7-trihydroxyflavone, 3-O-methyl-2,3-trans-fustin, 3-O-galloyl-2,3-trans-fustin); anthocyanins (leucodelfinidine, leucocyanidine, delfinidine 3-galactoside, cyanidine 3-galactoside, petunidine 3-glucoside, delfinidine 7-glucoside, cyanidine 3-glucoside-7-rhamnoside); essential oil (limonene, (Z)- $\beta$-oximene, (E)- $\beta$-oximene); gallic tannin (gallic acid), methyl gallate, gallocatechin, pentagalloyl glucose, biauron, $\beta$-resorcylic acid and 3-O- $\beta$-sitosterol glucoside (Hegnauer, 1964; Tanchev \& Timberlake, 1969; Westernburg et al., 2000; Demirci, Demirci, \& Baser, 2003; Kultur \& Bitis, 2007; Novakovic et al., 2007; Dulger, Hacioglu, \& Bilen, 2009; Özbek et al., 2019; Novakovic et al., 2019).

There are studies in the literature showing that different extracts obtained from the leaves, stem and aerial parts of C. coggygria have antimicrobial and antifungal activity (Tunc, Hoş, \& Guneş, 2013; Marcetić et al., 2013; Matic, Stanic, Solujic, Milosevic, \& Niciforovic, 2011). However, a report on compounds that may be responsible for the antimicrobial activity of this plant has not been published so far. To the best of our knowledge, this study is the first to find compounds that may be responsible for the activity of the ethyl acetate extract, which has been found to have potent antifungal activity. Therefore, the aim of our current study is to evaluate antimicrobial activities of the various extracts obtained by Soxhlet and maceration from $C$. coggyria and to isolate the compounds that may be responsible for the activity of the extract that is showing the best activity.

\section{MATERIALS AND METHODS}

\section{Plant material}

C. coggygria leaves were collected in the flowering periods from the Kirklareli province of Turkey and identified by Dr. Sukran Kultur, a botanist of the Faculty of Pharmacy, University of Istanbul. Voucher specimens were deposited in the Herbarium of the Faculty of Pharmacy, Istanbul University (ISTE No: 80926).

\section{Extraction}

C. coggygria leaves were dried in the shade and powdered by a mechanical grinder. A total of 20 grams of powdered material was extracted with solvents of increased polarity such as petroleum ether, chloroform, diethylether, ethyl acetate, methanol using Soxhlet apparatus and extraction was continued until the solution became colorless. A total of 20 grams of powdered material was separately extracted with $96 \%$ ethanol and water using maceration method. Also, about $300 \mathrm{~g}$ of the plant was weighed for isolation and similar extraction procedures described above were carried out.

\section{Antimicrobial activity}

In this study, the in vitro antimicrobial activities of the extracts and isolated compounds was determined using the microbroth dilution technique described by the Clinical and Laboratory Standards Institute (CLSI) (CLSI, 2006; CLSI, 2008). The minimum inhibitory concentrations (MICs) of the extracts were investigated against Staphylococcus aureus ATCC 6538, S. epidermidis ATCC 12228, Escherichia coli ATCC 25922, Klebsiella pneumoniae ATCC 4352, Pseudomonas aeruginosa ATCC 27853, Proteus mirabilis ATCC 14153, Candida albicans ATCC 10231, C parapsilosis, ATCC 22019, C tropicalis ATCC 750. Serial twofold dilutions ranging from 5000 to $4.8 \mu \mathrm{g} / \mathrm{mL}$ were prepared in Mueller-Hinton broth (MHB) (Difco,Detroit, MI, USA) for the bacteria and RPMI-1640 medium buffered to $\mathrm{pH} 7.0$ with MOPS for yeast strain were used as the test medium. (Sigma, St. Louis, MO, USA) medium for the yeast. DMSO was used as a solvent for the extracts. Each well was inoculated with $50 \mu \mathrm{L}$ of a $4-6 \mathrm{~h}$ broth culture to give a final concentration of $5 \times 10^{5} \mathrm{cfu} / \mathrm{mL}$ for the bacteria and $0.5 \times 10^{3}$ to $2.5 \times 10^{3} \mathrm{cfu} / \mathrm{mL}$ for the yeast in the test trays. The trays were covered and placed in plastic bags to prevent evaporation. The trays containing MHB were incubated at $37^{\circ} \mathrm{C}$ for $24 \mathrm{~h}$, while those containing theRPMI-1640 medium were incubated at $30^{\circ} \mathrm{C}$ for $48 \mathrm{~h}$. The MIC of each extract and isolated compounds were defined as the lowest concentration of compound required for complete inhibition of visible growth. Ciprofloxacin and fluconazole were used as reference antibimicrobials for bacteria and yeast, respectively. Also, as a control, the antimicrobial effects of the dimetil sulfoxide were investigated against test microorganisms. According to the values of the controls, the results were evaluated. The MIC values of the ciprofloxacin and fluconazole were within the accuracy range in CLSI throughout the study (CLSI, 2014).

\section{Isolation of active compounds from CCEA extract}

In the antimicrobial activity experiment, the CCEA showed the best antibacterial and antifungal activity among all extracts (Table 1). Therefore, CCEA was chosen for isolation. The CCEA (1.91 g) was fractionated by CC on polyamide, eluting with $\mathrm{CH}_{3} \mathrm{OH} / \mathrm{H}_{2} \mathrm{O}$ mixture in increasing polarity to yield thirty fractions (Figure 1). Fractions showing similar TLC profiles were combined to give seven sub-fractions (F1-F7, F8-F10, F11-F14, F15-F17, F19-F21, F22-F23, F24-F30). When the fractions were examined on the TLC plate, isolation was continued with F11- 
Table 1. Antimicrobial activity of various extracts from Cotinus coggygria leaves.

\begin{tabular}{|c|c|c|c|c|c|c|c|c|c|}
\hline \multirow{2}{*}{ Microorganisms } & $\mathrm{CCP}$ & $\operatorname{ccc}$ & CCD & CCEA & CCM & CCE & CCW & CPFX & FCZ \\
\hline & \multicolumn{9}{|c|}{ MIC values $(\mu \mathrm{g} / \mathrm{mL})$} \\
\hline $\begin{array}{l}\text { Staphylococcus } \\
\text { aureus }\end{array}$ & - & - & - & - & - & - & - & & \\
\hline $\begin{array}{l}\text { Staphylococcus } \\
\text { epidermidis }\end{array}$ & - & - & - & - & - & - & - & & \\
\hline Escherichia coli & - & - & - & - & - & - & - & & \\
\hline $\begin{array}{l}\text { Klebsiella } \\
\text { pneumoniae }\end{array}$ & - & - & - & - & - & - & - & & \\
\hline $\begin{array}{l}\text { Pseudomonas } \\
\text { aeruginosa }\end{array}$ & - & - & - & - & - & - & - & & \\
\hline Proteus mirabilis & - & - & - & 156 & - & - & - & 0.31 & \\
\hline Candida albicans & - & - & 39 & 4.9 & 4.9 & 4.9 & 9.8 & & 1 \\
\hline
\end{tabular}

F14 fraction, where the major compounds appeared to be the most pure. F11-F14 was repeatedly chromatographed on a Sephadex $\mathrm{LH}-20$ column, eluted with $\mathrm{CH}_{3} \mathrm{OH}$ and then combined sub-fractions were re-chromatographed by preparative TLC with toluene: acetone: formic acid (5:5:1) to give gallic cid (25.7 mg) and methyl gallate (17.4 mg) (Figure 1) .

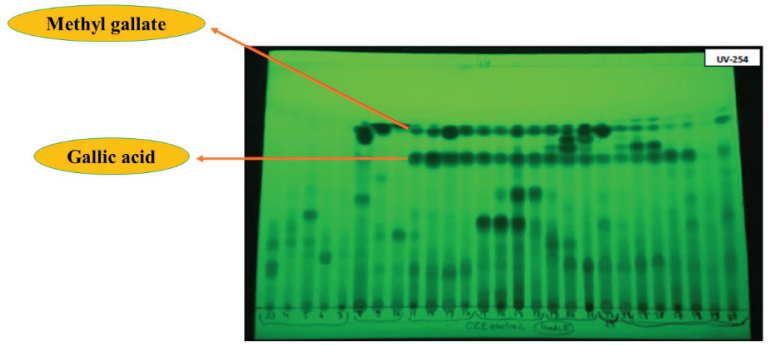

Figure 1. Thin layer chromatography (TLC) chromatogram of fractions of CCEA.

\section{RESULTS AND DISCUSSION}

In this study, the antimicrobial activities of various extracts obtained by different extraction methods from C. coggygria as well as the major compounds isolated from the active extract were investigated. The antimicrobial activities of extracts were investigated against S. aureus ATCC 6538, S. epidermidis ATCC 12228, E. coli ATCC 25922, K. pneumoniae ATCC 4352, P. aeruginosa ATCC 27853, P. mirabilis ATCC 14153, C. albicans ATCC 10231. Saraiva et al. (2011) suggested that plant extracts with MIC values of $<100 \mu \mathrm{g} / \mathrm{mL}$ were considered to be highly active antimicrobial agents; those with MICs of 100 to $500 \mu \mathrm{g} /$ $\mathrm{mL}$ were defined as active; those with MICs of 500 to 1000 $\mu \mathrm{g} / \mathrm{ml}$ were defined as moderately active; those with MICs of 1000 to $2000 \mu \mathrm{g} / \mathrm{mL}$ were considered to have low activity; and those with MICs of $>2000 \mu \mathrm{g} / \mathrm{ml}$ were defined as inactive. According to this view, CCD, CCEA, CCM, CCE and CCW extracts showed significant antifungal activity against $C$. albicans with MIC values of 39, 4.9, 4.9, 4.9 and $9.8 \mu \mathrm{g} / \mathrm{mL}$, respectively. In particular, the effects of the last four extracts against this fungus were very strong. In addition, none of the extracts, except the CCEA extract, had any effect against the bacteria used in this study. The CCEA extract exhibited good antibacterial activity against $P$. mirabilis with a MIC value of $156 \mu \mathrm{g} / \mathrm{mL}$ (Table 1). In a study conducted by Tunç et al. (2013), antibacterial effects of petroleum ether, chloroform, acetone, methanol, ethanol and distilled water extracts from the leaves of C. coggygria on S. epidermidis, E. coli, Salmonella typhimurium, Enterococcus faecalis, P. aeruginosa, S. aureus, and Bacillus subtilis were investigated and it was revealed that distilled water and methanol extracts showed good activity against S. aureus, S. epidermidis, and E. faecalis. In addition, it was found that distilled water extract had the highest activity with $22 \mathrm{~mm}$ inhibition zone against E. faecalis among these extracts (Tunç et al., 2013). In another study, Marcetic et al. (2013) tested antimicrobial activities of $70 \%$ acetone extract obtained from young shoots which included leaves and branches of C. coggygria and its chloroform, ethyl acetate and water fractions against S. aureus, S. epidermidis, Micrococcus luteus, E. faecalis, B. subtilis, P. aeruginosa, E. coli, K. pneumonia, C albicans (ATCC 10259 and ATCC 24433) and reported that the extracts showed antimicrobial activity with MIC values in the range of 3.1-200 $\mu \mathrm{g} / \mathrm{mL}$ (Marcetić et al., 2013) Additionally, Matic et al. (2011) examined antibacterial and antifungal effects of the methanol extract obtained by Soxhlet from the stem of C. coggygria against B. subtilis, K. pneumoniae, E. coli, S. aureus, Micrococcus lysodeikticus, C. albicans and found that the MIC values of extract were in the range of $125-250 \mu \mathrm{g} / \mathrm{mL}$. When compared with our current study, it was seen in previous studies that extracts from different parts of C. coggygria have antibacterial effects against various bacterial species. In the current study, it was observed that antibacterial activities of all the extracts were quite weak except for the activity shown by CCEA extract against $P$. mirabilis. However, the antifungal activity values of the extracts against C. albicans were close to or higher than previous studies. This may be due to the fact that collection time, growth place, extracted part of the plant as well as 
the extraction method, seasonal changes, growth stage and climate conditions are different.

Two major compounds, gallic acid and methyl gallate, were isolated from the CCEA extract, which showed the best antimicrobial activity. All isolated compounds were analyzed by spectroscopic methods ( ${ }^{1} \mathrm{H}$ NMR, ${ }^{13} \mathrm{C}$ NMR-APT, HMBC) and their data were compared with those reported in the literature (Xu et al., 2015; Banday et al., 2012). Also, gallic acid isolated in this study was compared on TLC with an authentic sample. The compounds were identified as follows:

Gallic acid: Colourless amorphous powder. ${ }^{1} \mathrm{H}$ NMR $(500 \mathrm{MHz}$, $\mathrm{CD}_{3} \mathrm{OD}, \delta, \mathrm{ppm}, \mathrm{J} / \mathrm{Hz}$ ): 7.04 (s, 2H, H-2/H-6) (Figure 2).

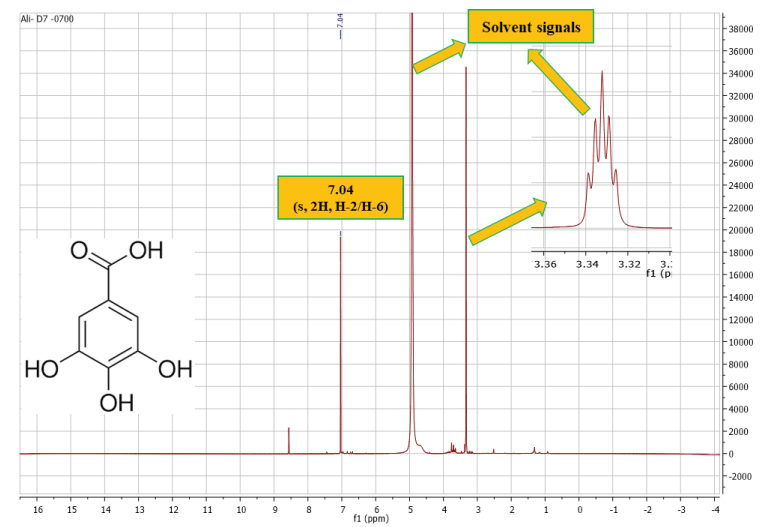

Figure 2. ${ }^{1} \mathrm{H}-\mathrm{NMR}(500 \mathrm{MHz}, \mathrm{CD} 3 \mathrm{OD})$ spectrum of gallic acid.

Methyl gallate: Colourless amorphous powder. ${ }^{1} \mathrm{H}$ NMR (500 MHz, CD $\mathrm{OD}_{1}$, $, \mathrm{ppm}, \mathrm{J} / \mathrm{Hz}$ ): 6.95 (s, 2H, H-2/H-6), 3.71 (s, $\left.3 \mathrm{H},-\mathrm{OCH}_{3}\right) .{ }^{13} \mathrm{C}$ NMR $\left(125 \mathrm{MHz}, \mathrm{CD}_{3} \mathrm{OD}, \delta, \mathrm{ppm}\right): 169.05$ (C-7), 146.52 (C-3/C-5), 139.74 (C-4), 121.54 (C-1), 110.11 (C-2/C-6), $52.30\left(\mathrm{OCH}_{3}\right)$ (Figure 3).

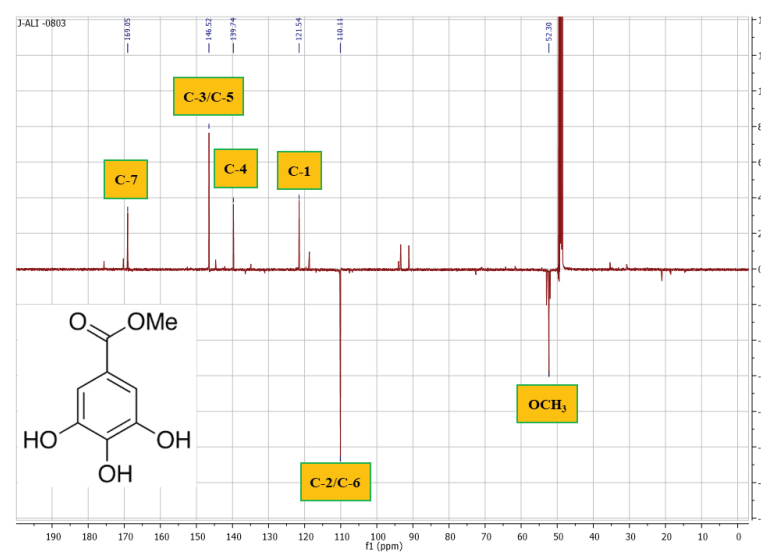

Figure 3. ${ }^{13} \mathrm{C}-\mathrm{NMR}$ (APT) $\left(125 \mathrm{MHz}, \mathrm{CD}_{3} \mathrm{OD}\right)$ spectrum of methyl gallate.

The antimicrobial activities of major compounds were investigated against S. aureus, S. epidermidis, E. coli, K. pneumoniae, P. aeruginosa, P. mirabilis, C. albicans, C. parapsilosis, C. tropicalis. Gallic acid showed moderate antibacterial activity against $S$. aureus and S. epidermidis with MIC values of 78 and $156 \mu \mathrm{g} /$ $\mathrm{mL}$ while it showed weak antibacterial effect against $E$. coli and
P. aeruginosa with MIC value of $625 \mu \mathrm{g} / \mathrm{mL}$ (for both bacteria), respectively. Methyl gallate did not show any antibacterial effect. Gallic acid exhibited strong antifungal activity against $C$. albicans and C. tropicalis with MIC value of $9.8 \mu \mathrm{g} / \mathrm{mL}$ (for both fungi) while it possessed moderate activity $156 \mu \mathrm{g} / \mathrm{mL}$ against C. parapsilosis. Methyl gallate showed moderate antifungal effect against C. albicans, C. parapsilosis and C. tropicalis with MIC values of 312 and $156 \mu \mathrm{g} / \mathrm{mL}$ (for the last two fungi), respectively (Table 2). Especially considering the strong antifungal effect of gallic acid against different $C$. species, it suggests that this compound, with other phenolic compounds, may be highly responsible for the activity of CCEA, which exhibits strong antifungal effect against C. albicans. Also, previous studies showing that gallic acid has strong antifungal activity against Candida species support the results of our current study ( $\mathrm{Li}$ et al., 2017; Alves et al., 2014).

\section{Table 2. Antimicrobial activity of major compounds} isolated from CCEA.

\begin{tabular}{|c|c|c|c|c|}
\hline \multirow[t]{2}{*}{ Microorganisms } & $\begin{array}{l}\text { Gallic } \\
\text { acid }\end{array}$ & $\begin{array}{c}\text { Methyl } \\
\text { gal- } \\
\text { late }\end{array}$ & CPFX & FCZ \\
\hline & \multicolumn{4}{|c|}{ MIC values $(\mu \mathrm{g} / \mathrm{mL})$} \\
\hline $\begin{array}{l}\text { Staphylococcus } \\
\text { aureus }\end{array}$ & 78 & - & 0.25 & \\
\hline $\begin{array}{l}\text { Staphylococcus } \\
\text { epidermidis }\end{array}$ & 156 & - & & \\
\hline Escherichia coli & 625 & - & & \\
\hline $\begin{array}{l}\text { Klebsiella pneu- } \\
\text { moniae }\end{array}$ & - & - & & \\
\hline $\begin{array}{l}\text { Pseudomonas aeru- } \\
\text { ginosa }\end{array}$ & 625 & - & & \\
\hline Proteus mirabilis & - & - & & \\
\hline Candida albicans & 9.8 & 312 & & 1 \\
\hline Candida parapsilosis & 156 & 156 & & \\
\hline Candida tropicalis & 9.8 & 156 & & \\
\hline
\end{tabular}

\section{CONCLUSION}

These results indicate that $C$. coggygria have strong antifungal activity confirming its ethnobotanical use for the treatment of fungal infections. It also shows that the compound that is significantly responsible for the activity of CCEA, one of the extracts with strong antifungal effect, is gallic acid together with other phenolic compounds.

Peer-review: Externally peer-reviewed.

Author Contributions: Conception/Design of Study- A.S., L.B.; Data Acquisition- A.Ş., A.S.B.T., Ş.K., L.B.; Data Analysis/Interpretation- A.Ş., A.S.B.T., Ş.K., L.B.; Drafting Manuscript- A.Ş., L.B.; Critical Revision of Manuscript- A.S.., A.S.B.T., Ş.K., L.B.; Final Approval and AccountabilityA.Ş., A.S.B.T., Ş.K., L.B.; Technical or Material Support- Ş.K.; SupervisionA.S.B.T., S.K., L.B. 
Conflict of Interest: The authors have no conflict of interest to declare.

Financial Disclosure: Authors declared no financial support.

\section{REFERENCES}

- Aksoy, H., Sancar, M., Sen, A., Okuyan, B., Bitis, L., Uras F. ... Izzettin, F.V. (2016a). The effect of topical ethanol extract of Cotinus coggygria Scop. on cutaneous wound healing in rats. Natural Product Research, 30(4), 452-455.

- Aksoy, H., Sen, A., Sancar, M., Sekerler, T., Akakin, D., Bitis, L. ... Izzettin F. V. (2016b). Ethanol extract of Cotinus coggygria leaves accelerates wound healing process in diabetic rats. Pharmaceutical Biology, 54(11), 2732-2736.

- $\quad$ Alves, C. T., Ferreira, I. C. F. R., Barros, L., Silva, S., Azeredo, J., \& Henriques, M. (2014). Antifungal activity of phenolic compounds identified in flowers from North Eastern Portugal against Candida species. Future Microbiology, 9(2), 139-146.

- Banday, J. A., Mir, F. A., Farooq, S., Qurishi, M. A., Koul, S., \& Razdan, T. K. (2012). Salicylic acid and methyl gallate from the roots of Conyza canedensis. International Journal of Chemical and Analytical Science, 3(2),1305-1308.

- Clinical and Laboratory Standards Institute (2006). Methods for dilution antimicrobial susceptibility tests for bacteria that grow aerobically: Approved Standard M7-A7. Wayne, USA.

- Clinical ans Laboratory Standards Institute (2008). Reference Method for Broth Dilution Antifungal Susceptbility Testing of Yeasts; Approved Standart M27-A3. Wayne, USA.

- Clinical and Laboratory Standarts Institute (2014). Performance standarts for antimicrobial susceptibility testing; 24th informational supplement. M 100-S24:CLSI. Wayne, USA.

- Davis P. H. (1967). Flora of Turkey and the East Aegean Islands (pp. 543). Edinburgh, UK: Edinburgh University Press.

- Demirci, B., Demirci, F., \& Baser, K. H. C. (2003). Composition of the essential oil of Cotinus coggygria Scop. from Turkey. Flavour and Fragrance Journal, 18(1), 43-44.

- Dulger, B., Hacioglu, N., \& Bilen, S. (2009). Antimicrobial activity of Cotinus coggygria from Turkey. Asian Journal of Chemistry, 21(5), 4139-4140.

- Hegnauer, R. (1964). Chemotaxonomie der Pflanzen. Basel und Stuttgart: Birkhauser Verlag.

- Kültür, S. (2007). Medicinal plants used in Kirklareli province (Turkey). Journal of Ethnopharmacology, 111(2), 341-364.

- $\quad$ Kultur, S., \& Bitis, L. (2007). Anatomical and preliminary chemical studies on the leaves of Cotinus coggygria Scop. (Anacardiaceae). Journal of Faculty of Pharmacy of Istanbul, 39, 65-71.

- $\quad$ Li, Z-J., Liu M., Dawuti G., Dou Q., Ma Y., Liu H-G., \& Aiba S. (2017). Antifungal activity of gallic acid in vitro and in vivo. Phytotherapy Research, 31(7), 1039-1045.

- Madikizela, B., Aderogba, M. A., Finnie, J. F., \&Van Staden, J. (2014). Isolation and characterization of antimicrobial compounds from Terminalia phanerophlebia Engl. \& Diels leaf extracts. Journal of Ethnopharmacology, 156, 228-234.
Matic, S., Stanic, S., Solujic, S., Milosevic, T., \& Niciforovic N. (2011). Biological properties of the Cotinus coggygria methanol extract. Periodicum biologorum, 113(1), 87-92.

- Marcetić M., Bozić D., Milenković, M., Malesević, N., Radulović, S., \& Kovacević N. (2013). Antimicrobial, antioxidant and anti-inflammatory activity of young shoots of the smoke tree, Cotinus coggygria Scop. Phytotherapy Research, 27(11), 1658-1663.

Novakovic, M., Vuckovic, I., Janackovic, P., Sokovic, M., Filipovic, A., Tesevic, V., \& Milosavljevic, S. 2007. Chemical composition, antibacterial and antifungal activity of the essential oils of Cotinus coggygria from Serbia. Journal of the Serbian Chemical Society, 72(11), 1045-1051.

- Novakovic, M., Djordjevic, I., Todorovic, N., Trifunovic, S., Andjelkovic, B., Mandic, B., Jadranin, M., Vuckovic, I., Vajs, V., Milosavljevic, S., \& Tesevic, V. 2019. New aurone epoxide and auronolignan from the heartwood of Cotinus coggygria Scop. Natural Product Research, 33(19), 2837-2844.

- $\quad$ Özbek, H., Yuca, H., Gözcü, S., Dursunoğlu, B., Özenver, N., Güvenalp Z., Kazaz C., Önal, M., \& Demirezer L.Ö. 2019. Phenolic compounds from Cotinus coggygria Scop. with alpha glucosidase inhibition. FABAD Journal of Pharmaceutical Sciences, 44(2), 127-132.

- Saraiva, A. M., Castro, R. H. A., Cordeiro, R. P., Peixoto Sobrinho, T. J. S., Castro, V. T. N. A., Amorim, E. L. C., Xavier H. S., Pisciottano M. N. C. 2011. In vitro evaluation of antioxidant, antimicrobial and toxicity properties of extracts of Schinopsis brasiliensi Engl. (Anacardiaceae). African Journal of Pharmacy and Pharmacology, 5(14), 1724-1731.

- $\quad$ Singh, M., Pandey, N., Agnihotri, V., Singh, K. K., \& Pandey A. (2017). Antioxidant, antimicrobial activity and bioactive compounds of Bergenia ciliata Sternb.: A valuable medicinal herb of Sikkim Himalaya. Journal of Traditional and Complementary Medicine, 7(2), 152-157.

- $\quad$ Tanchev, S. S., \& Timberlake, C. F. (1969). Anthocyanins in leaves of Cotinus coggygria. Pyhtochemistry, 8(12), 2367-2369.

- Tunç, K., Hoş, A., \& Güneş, B. (2013). Investigation of antibacterial properties of Cotinus coggygria from Turkey. Polish Journal of Environmental Studies, 22(5), 1559-1561.

- $\quad$ Xu, J., Zhao, Q., Wei, L., Yang, Y., Xu, R., Yu, N., \& Zhao, Y. (2015). Phytochemical composition and antinociceptive activity of Bauhinia glauca subsp. hupehana in rats. PLoS one, 10(2), e0117801.

- Westernburg, H. E., Lee, K. J., Lee, S. K., Fong, H. H. S., Bremen, R. B. V., Pezutto, J. M., \& Kinghorn, A. D. 2000. Activity-guided isolation of antioxidative constituents of Cotinus coggygria. Journal of Natural Products, 63(12), 1696-1698.

- Zhang, L., Ravipati, A. S., Koyyalamudi, S.R., Jeong, S. C., Reddy N., Bartlett J.... Vicente F. (2013). Anti-fungal and anti-bacterial activities of ethanol extracts of selected traditional Chinese medicinal herbs. Asian Pacific Journal of Tropical Medicine, 6(9), 673-681. 